\title{
A Case Report of Calcifying Epithelioma of Malherbe (Pilomatrixoma) Mimicking Breast Carcinoma in Male Patient
}

\author{
Maria Marta Martins, Adrienne Pratti Lucarelli, José Mendes Aldrighi, Aline Forattini \\ Department of Gynecology and Obstetrics of the Irmandade da Santa Casa de Misericórdia de São Paulo, \\ São Paulo, Brazil \\ Email: adrilucarelli@terra.com.br
}

Received 9 March 2014; revised 8 April 2014; accepted 7 May 2014

Copyright (C) 2014 by authors and Scientific Research Publishing Inc. This work is licensed under the Creative Commons Attribution International License (CC BY). http://creativecommons.org/licenses/by/4.0/

C) (i) Open Access

\begin{abstract}
Pilomatricoma or calcifying epithelioma of Malherbe is a rare benign tumor of the skin and/or the subcutaneous tissue originating from the hair matrix. It is usually seen in children and adolescents, however a smaller second peak of onset is seen in the elderly. The head, neck, or upper extremities are the most common anatomical sites of pilomatricomas, being less frequently seen on the trunk and lower extremities, and very rarely have they been diagnosed in the breast. Its malignant counterpart, pilomatrix carcinoma, is rare and found more often in men. Due to its incapacity of regression, treatment consists of surgical excision. We present the case of a man with a pilomatrixoma of the breast, presenting as ACR BI-RADS 4, and we review the literature regarding pilomatrixomas.
\end{abstract}

\section{Keywords}

Male, Pilomatrixoma, Diagnosis, Treatment

\section{Introduction}

A 47-year-old male referred painful, a two-month-old node in the right breast. He also reported blaunt trauma to the thorax 6 months earlier, secondary to a fall. He denied personal and family history of malignancy.

Physical examination revealed a firm subcutaneous nodule of $2 \mathrm{~cm}$ in the right breast, $0.5 \mathrm{~cm}$ from the areola and noaxilarylymph node alterations. There was no nipple discharge. The left breast did not present any abnormalities.

Mammography: Birads IV is due to node with indistinct limits and microcalcifications (Figure 1).

Ultrassonography: Birads III is due to lobulated node, isoechoic, parallel to the skin, with multiple hyperechoic 
foci corresponding to calcifications seen on mammogram. Excisional biopsy was performed under local anesthesia. Macroscopically, the mass was white in appearance and well circumscribed. Histopathology revealed a pilomatrixoma, and the histology is presented in Figure 2. The tumor is well-circumscribed with islands of basaloid cells located both peripherally and centrally. Basaloid matricalgerminative cells blend into keratinized ghost cells.

No recurrences or surgery-associated complications were observed in the follow-up period.

\section{Discussion}

Pilomatrixoma, also known as pilomatricoma or calcifying epithelioma of Malherbe, is a benign neoplasm that derives from hair follicle matrix cells. In 1880, Malherbe and Chenantais first described this lesion, referred to as the calcifying epithelioma, though it was thought to derive from sebaceous glands. The term pilomatrixoma was introduced in a publication by Forbis and Helwig in 1961 to better convey the histological source [1].

Pilomatrixomas are typically found in the head and neck region, but also occur in the upper extremities and are rarely reported in other sites. Only few breast pilomatricomas have been reported [2] [3]. Malignant pilomatricomas have been reported, suggesting that all pilomatricomas should be surgically removed. It is locally aggressive and can recur after excision. In several cases, metastasis of the malingnant version has been seen [4]. Many key features are similar between the benign and malignant counterparts; primary differences of the malignant subtype include a high mitotic rate with atypical mitoses, central necrosis, infiltration of the skin and soft

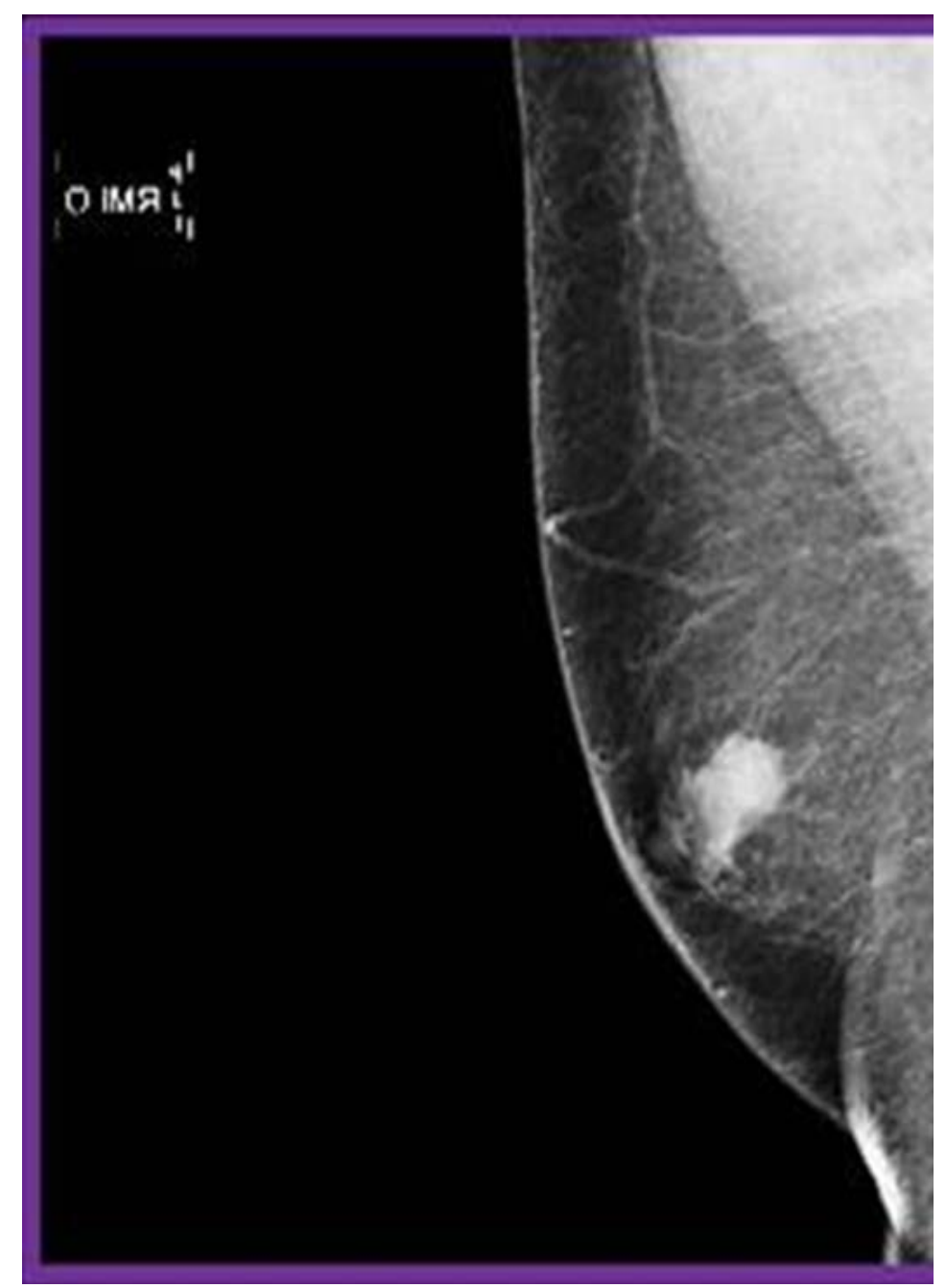

Figure 1. Mamography. 


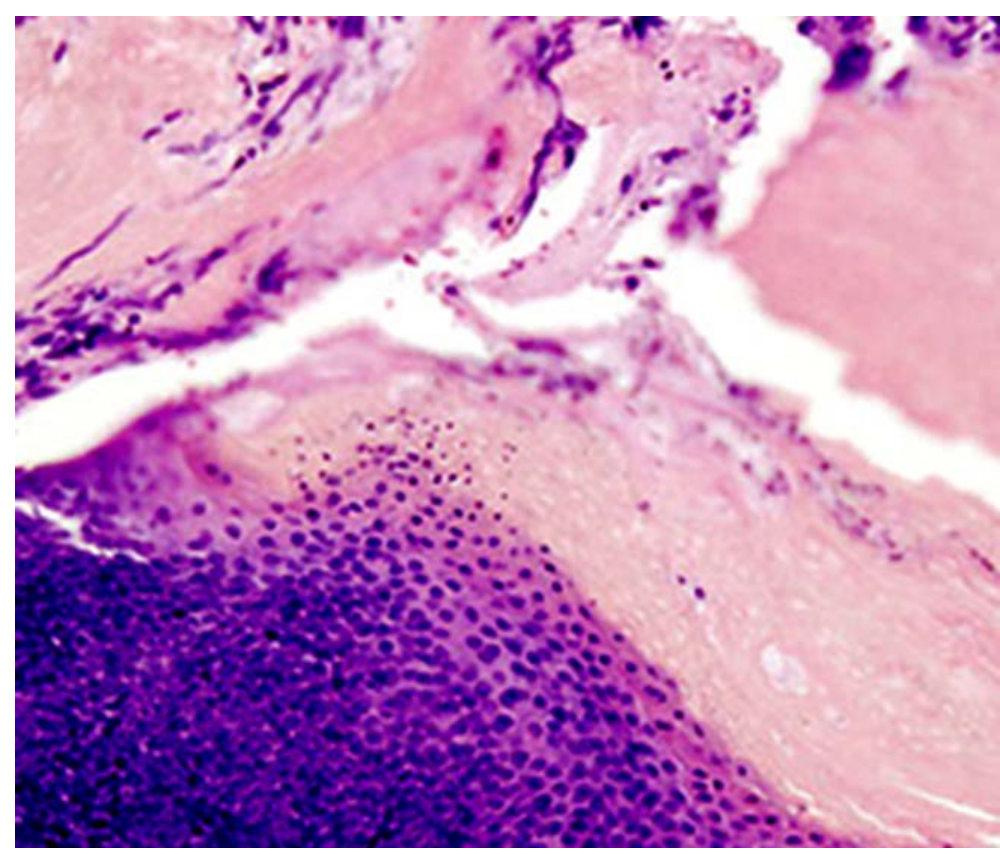

Figure 2. Pilomatrixoma involving deep dermis and subcutis. The tumor is well-circumscribed with islands of basaloid cells located both peripherally and centrally. Most of the tumor, however, is composed of eosinophilic keratin debris and a mixed inflammatory infiltrate.

tissue, and invasion of blood and lymphatic vessels [4].

The clinical presentation is typically that of an asymptomatic, superficial, solitary, firm mass that is often accompanied by a reddish-blue discoloration of the overlying skin. The mass is usually painless unless it becomes inflamed or infected. A pilomatrixoma forms when cells abnormally harden and form a mass under the skin. The cells involved are similar to hair follicle cells [5].

The histopathologic features of a pilomatrixoma include a well demarked tumor often surrounded by a connective tissue capsule. It is usually located in the dermal or subcutaneous layers of the skin and consists of basaloidcells that lose their nuclei; these cells are known as "ghosts" (or shadow) and often show cystic change. As the tumor matures, degeneration of these central basaloid cells occurs. It is important to note, however, that these ghost cells, though quite specific, are not unique to pilomatrixomas. Different degrees of inflammatory reactions may occur. Foreign body giant cells, keratin debris, and central calcifications are also characteristic. Calcification has been noted in 70 to 85 percent of cases. It has been suggested that osteopontin (a protein marker associated with bone production) may be produced by macrophages and play a role in the deposition of calcium phosphate in the shadow cell nests [6].

The cause of pilomatrixoma is unknown. However, some genetic changes have been found in the affected hair cells (an overactive proto-oncogene called BCL-2 suggests the normal process of cell death is suppressed and mutations in CTNNB1 suggest loss of regulation of a protein complex called beta-catenin/LEF). In one study of 10 pilomatrixoma lesions, all immunostaining results were strongly positive for $B C L 2$. This is a proto-oncogene that helps suppress apoptosis in benign and malignant tumors; these data suggest that faulty suppression of apoptosis contributes to the pathogenesis of these tumors [2].

Investigators have demonstrated that the proliferating cells of human pilomatrixomas show prominent staining with antibodies directed against LEF-1 (a marker for hair matrix cells). Evidence also indicates that S100 proteins can be used as biochemical markers in characterization of pilomatrixomas [2] [6] [7]. These data provide biochemical support of morphological evidence that these tumors are derived from hair matrix cells. Furthermore, investigators have shown that at least $75 \%$ of persons with pilomatrixomas have mutations in the CTNNB1gene; these data directly implicates beta-catenin/LEF misregulation as the major cause of hair matrix cell tumorigenesis in humans. Although the etiology of pilomatrixoma is not completely understood, there are suggestions that an activating mutation in the $\beta$-catenin gene mapped to chromosome 3 p22-23 plays a major 
role in this tumor genesis. Although pilomatrixomausually appears sporadically, some association has been found between this tumor in the pediatric population and disorders such as myotonic dystrophy, Rubinstein Taybi syndrome, Turner syndrome, Gardnersyndrome, xerodermapigmentosum and basal cell nevus syndrome [2] [6].

Despite a very low propensity for malignant degeneration, surgical excision is the treatment of choice for pilomatrixomas. These tumores are not associated with high rates of mortality. Very large tumorscan cause considerable discomfort but are uncommon. Pilomatrixoma carcinomas are also uncommon, but they are locally invasive and can cause metastases to the bones, lungs, and lymph nodes, and even death [2] [4] [8].

Differential diagnosis includes: seborrheic keratosis, dermal nevus, epidermal inclusion cyst, branchial remnants, atypical mycobacterial infections, parotid lesions, pre-auricular sinuses, ossifying hematoma, giant cell tumor, chondroma and foreign-body reaction, and basal cell carcinoma. Much less frequently, dermal or subdermal lesions can represent or hemangioma breast carcinoma. Rarely cases of polimatrixoma can be associated with myotonic dystrophy and Rubinstein-Taybi syndrome. Factors contributing to misdiagnosis include cystic lesions with varying consistency, punctum-like appearance, atypical location, and absence of clinically recognizable calcification [9]-[12].

Fine needle aspiration diagnosis of pilomatrixoma (FNA) - The wide range of cell differentiation in conjunction with pertinent clinical findings, absence of nuclear atypia, tumor diathesis, mitotic figures and awareness of the entity lead to the correct diagnosis of pilomatrixoma. The most dangerous mistake in FNA diagnosis of PMX regards a diagnosis of primary malignant or metastatic cutaneous lesions [13].

Two Pilomatricoma ultrasound patterns are described in literature: the completely calcified nodule and the hypoechoic nodule with internal calcific foci. The majority of superficial tumors are benign, and the management is frequently based on results of the triple test (physical exam, imaging and biopsy) [9] [13] [14].

Surgery is curative and recurrence after excision is rare. Complete excision is the preferred treatment, as spontaneous regression has not been described. In certain cases, it is necessary to excise the overlying skin to remove tumor adherent to the dermis, but care should be used to preserve the overlying skin. Adherence to deep structures is not noted. The risk of recurrence is as high as $4 \%$, although it is generally accepted that rates of recurrence with complete excision is low [4] [12]. Malignant transformations are rare and are limited to those occurring in middle aged or elderly patients [4]. A conservative approach of interval follow-up for any small superficial breast mass with benign imaging characteristics may be considered [11] [12].

\section{Conclusion}

Pilomatrixomas represent table with benign neoplasm of the rare differential diagnosis with breast cancer. Usually, its diagnosis is easily based on clinical findings but ultrasonography is a useful and non invasive procedure helping to determine the depth of lesion. Spontaneous regression is never observed. Treatment consists of the simple surgical removal of the tumor. Early diagnosis is important so that unnecessary, aggressive surgery can be avoided. Recurrence is rarely observed and when multiple recurrences do occur, further investigation of carcinoma of the pilomatrix should be made.

\section{References}

[1] Hamilton, A., Young, G.I. and Davis, R.I. (1987) Pilomatrixoma Mimicking Breast Carcinoma. British Journal of Dermatology, 116, 585-586. http://dx.doi.org/10.1111/j.1365-2133.1987.tb05883.x

[2] Farrier, S. and Morgan, M. (1997) bcl-2 Expression in Pilomatricoma. American Journal of Dermatopathology, 19, 254-257. http://dx.doi.org/10.1097/00000372-199706000-00009

[3] Dutta, R., Boadle, R. and Ng, T. (2001) Pilomatrix Carcinoma: Case Report and Review of the Literature. Pathology, 33, 248-251.

[4] Mikhaeel, N.G. and Spittle, M.F. (2001) Malignant Pilomatrixoma with Multiple Local Recurrences and Distant Metastases: A Case Report and Review of the Literature. Clinical Oncology, 13, 386-389.

[5] Yencha, M.W. (2001) Head and Neck Pilomatricoma in the Pediatric Age Group: A Retrospective Study and Literature Review. International Journal of Pediatric Otorhinolaryngology, 57, 123-128. http://dx.doi.org/10.1016/S0165-5876(00)00449-3

[6] Kizawa, K., Toyoda, M., Ito, M. and Morohashi, M. (2005) Aberrantly Differentiated Cells in Benign Pilomatrixoma Reflect the Normal Hair Follicle: Immunohistochemical Analysis of Ca-Binding S100A2, S100A3 and S100A6 Pro- 
teins. British Journal of Dermatology, 152, 314-320. http://dx.doi.org/10.1111/j.1365-2133.2004.06391.x

[7] Ali, M.Z. and Ali, F.Z. (2005) Pilomatrixoma Breast Mimicking Carcinoma. Journal of the College of Physicians and Surgeons Pakistan, 15, 248-249.

[8] Oliveira, E.L.C. and Ruffo Jr., F. (2010) Pilomatrixoma Mimicking Breast Cancer in Man. The Breast Journal, 16, 89-91. http://dx.doi.org/10.1111/j.1524-4741.2009.00852.x

[9] Charles, H.H., et al. (2011) Pilomatrixoma, Case Report. Journal of Clinical Imaging Science, 1, 56.

[10] Seok Jeong, M.D., Bong-Suk Oh, M.D., Soon-Jin Kim, M.D., Chi-Hyeong Yun, M.D., Min-Sun Beom, M.D. and DoWan Kim, M.D. (2011) Pilomatrix Carcinoma in the Chest Wall around an Eloesser Open Window-A Case Report. The Korean Journal of Thoracic and Cardiovascular Surgery, 44, 269-271.

[11] Guinot-Moya, R., Valmaseda-Castellon, E., Berini-Aytes, L. and Gay-Escoda, C. (2011) Pilomatrixoma. Review of 205 cases. Medicina Oral, Patologia Oral, Cirugia Bucal, 4, 16.

[12] Kenneth, R.W. and Michael, C. (2012) Imaging and Review of a Large Pre-Auricular Pilomatrixoma in a Child. World Journal of Radiology, 4, 228-230. http://dx.doi.org/10.4329/wjr.v4.i5.228

[13] Ieni, A., Todaro, P., Bonanno, A.M., Catalano, F., Catalano, A. and Giovanni, T. (2012) Limits of Fine-Needle Aspiration Cytology in Diagnosing Pilomatrixoma: A Series of 25 Cases with Clinico-Pathologic Correlations. Indian Journal of Dermatology, 57, 152-155. http://dx.doi.org/10.4103/0019-5154.94295

[14] Kenneth, R.W. and Michael, C. (2012) Imaging and Review of a Large Pre-Auricular Pilomatrixoma in a Child. World Journal of Radiology, 4, 228-230. http://dx.doi.org/10.4329/wjr.v4.i5.228 